Harm reduction

\section{Harm reduction: 25 years later}

\section{W A Farone}

\section{The cigarette industry has managed to avoid any real harm reduction in their products over the years}

M uch has been written in recent issues of Tobacco Control concerning harm reduction products as part of a public health strategy for dealing with tobacco use. The editorial by Kozlowski and colleagues ${ }^{1}$ advocated medicinal nicotine as part of the plan and discusses risks from other alternatives. They correctly point out that small changes in elimination of toxic ingredients are not very effective in reducing the dangers of smoking. Such small changes in a smoking product that is supposed to be a potentially less risky version of cigarettes actually perpetuate the continued marketing of very hazardous products, especially if the marketers insist that they leave the more risky product on the market. In this issue Breland and colleagues $^{2}$ discuss another marginally

reduced harm product called Advance ${ }^{\mathrm{TM}}$. The name is somewhat ironic given that the advance in harm reduction from the viewpoint of chemical exposure appears marginal at best.

When I joined Philip Morris in 1976 the plan to make cigarettes that caused less disease seemed relatively straightforward. Harm reduction could be achieved through practical application of dose-response concepts. Through a series of manoeuvres the cigarette industry has managed to avoid any real harm reduction making small steps of limited impact. In many cases tar levels for many popular brand versions such as various "Lights", "Ultra Lights", and "Low Tar" cigarettes have actually increased over the last 20 years. The illusion of lower sales weighted tar averages is based on a

Table 1 Versions of the Cambridge cigarette

\begin{tabular}{lllll}
\hline & \multicolumn{3}{l}{ Federal Trade Commission tar (mg) } \\
\cline { 2 - 5 } & Regular 100 & Lights 100 & Lights King & Full Flavor King \\
\hline November 1985 & 6.0 & & & \\
March 1986 & 5.5 & 11.3 & 12.0 & \\
March 1987 & 4.9 & 11.7 & 11.6 & 16.1 \\
November 1988 & 4.8 & & & \\
\hline
\end{tabular}

Table 2 Versions of the Benson \& Hedges cigarette

\begin{tabular}{|c|c|c|c|c|c|}
\hline & \multicolumn{5}{|c|}{ Federal Trade Commission tar (mg) } \\
\hline & Regular Box & Ultra Lights Box & Lights 100 & Multifilter & King Box \\
\hline November 1985 & 1.6 & 6.8 & 11.2 & 11.6 & 14.8 \\
\hline March 1986 & 1.6 & 5.9 & 10.8 & 11.4 & 14.9 \\
\hline March 1987 & 1.1 & 6.2 & 10.4 & 11.3 & 14.1 \\
\hline November 1988 & & 6.0 & 10.4 & 11.6 & 15.8 \\
\hline
\end{tabular}

Table 3 Versions of the Virginia Slims cigarette

\begin{tabular}{llll}
\hline & \multicolumn{2}{l}{ Federal Trade Commission tar (mg) } \\
\cline { 2 - 4 } & Lights Box 100 & Lights 120 & Regular 100 \\
\hline November 1985 & 9.4 & 13.5 & 14.6 \\
March 1986 & 9.2 & 13.9 & 13.9 \\
March 1987 & 8.7 & 13.3 & 14.1 \\
November 1988 & 8.1 & 13.3 & 14.9 \\
\hline
\end{tabular}

very small difference in actual Federal Trade Commission (FTC) tars in closely related versions of the major brands.

To illustrate the minor difference in tars between "Lights" and "Low Tar" versions of cigarettes, and also the confusion surrounding the use of descriptors such as "Lights", "Ultra Lights", etc, I have selected comparisons of three brands from the period 1985 to 1988. This period is selected as a reflection of the time when "Lights" brands and brand extensions were being introduced and manipulated based on the public perception that these brands conveyed reduced harm. All data are directly from the annual Philip Morris cigarette information reports for 1985 to $1988 .{ }^{3}$

Table l provides some results surrounding the introduction of a higher tar version of the Cambridge cigarette after entering the market in 1980 with a version advertised as the lowest tar brand (less than $0.1 \mathrm{mg}$ tar). As can be seen, a regular version was on the market in the 5-6 mg tar range while "Lights" were introduced in the 11$12 \mathrm{mg}$ tar range.

In table 2 several versions of the Benson \& Hedges cigarette are presented from the same period. A very low tar regular version was on the market while two higher tar "Lights" versions were sold. The difference between the "Multifilter" and Lights 100 versions are also negligible.

In table 3 data for the Virginia Slims cigarette show that the Lights 120 version has about the same tar as the regular 100, a tradition carried to the current time. Since there is no regular $120 \mathrm{~mm}$ version, Philip Morris cannot argue that for every version they call a "Light" there is a regular version with more tar.

These examples are typical of the confusion associated with even the small changes that might lead smokers to think they are getting some benefit with regard to harm reduction.

The cigarette industry makes the point that no public health body has recommended a means to provide a reduced risk cigarette and there is no clear path for them to follow. This is a lie since there is such a path that can be used in addition to, and not in place of, smoking cessation and medicinal nicotine. This path can force greater change sooner in the risk from cigarettes for those who are dependent on cigarettes to obtain their nicotine.

\section{PLAN TO REDUCE RISKS FROM SMOKING}

There was a logical plan to reduce the risks from active smoking over 25 years ago. It was based on known points of the dose-response curve for human smoke exposure. In addition to the smoker and non-smoker there are two other dose- 
response points to consider with regard to the toxic effects of cigarette smoke. First we recognise that by exposure to smoke we are dealing with exposure to a set of chemicals. The chemicals taken collectively form the common basis for comparison of risk. One of these risk levels is the level of exposure associated with environmental tobacco smoke (ETS) and the other is the exposure associated with pipe and cigar smoking. The reduced disease risk from the similar set of chemicals in ETS indicates that for meaningful harm reduction the chemical levels must be reduced by orders of magnitude. Even with tar levels of $1-3 \mathrm{mg}$ the smoker is getting far more toxic chemicals than they do from passive smoking. Thus, if significant reductions in disease risk are to be achieved, the chemical exposures from active smoking should be minimised to no greater than the levels associated with ETS. The inhalation of cigarette smoke is another important factor in determining exposure to the harmful chemicals in the cigarette smoke. The lower risk for lung cancer and respiratory disease seen in those only smoking pipe tobacco or cigars suggests that if cigarettes were made in such a way as to not facilitate deep inhalation of the smoke, the disease risk could be lowered substantially.

There is no reason not to apply traditional concepts of dose-response to cigarette smoke. If we act on the fact that the basic toxic chemicals are the same regardless of their source we can derive maximum allowable levels of various chemicals in cigarette smoke. We can propose the maximum allowable levels that will reasonably result in harm reduction. This can be based on environmental studies.

As an example, in March 2002 the California Environmental Protection Agency (CA EPA) released the latest status report on developing "safe harbor" levels for carcinogens and teratogens. ${ }^{4}$ Eventually all of the carcinogens and teratogens on the California Proposition 65 list will have levels defined that are nominated as values of daily exposure that will increase risk by less than 1 in 100000 . It should be noted that this list also includes tobacco smoke. Eventually CA EPA will have to provide an answer to the question of a "safe" level of cigarette smoke as they continue their work.

\section{DEVELOPING LESS DANGEROUS PRODUCTS}

Scientific publications with carefully laid out rationales for exposure levels will force the cigarette industry to make their products less dangerous. If such standards were in place the industry would no longer be able to argue that they have not been provided guidance. A smoker should not have to choose between risk levels. Smokers should only be able to choose between products that are first proven to meet some exposure standard that has a reasonable chance for reduced harm. After that standard is met the cigarette industry can determine how to make such products acceptable and compete in the marketplace if they still desire to do so.

Defined maximum exposure levels that can be modified as more data are acquired would aid the cigarette industry in meeting its obligation to develop products that do not cause disease. Studies of the type performed by CA EPA on toxic chemicals in cigarette smoke other than those they have already set would be useful. These new values, plus adoption of the California values for compounds like acetaldehyde, formaldehyde, etc, set a de facto standard for cigarettes that could be used to define defective products. These products will not be $100 \%$ safe since there still is some risk. The cigarette industry can maintain their mantra: "There is no such thing as a safe cigarette". They will not be able to avoid the "safer" cigarette issue, however, especially if every "safe harbour" level of a toxic chemical carries the acknowledgement that levels above this are unreasonably dangerous.

Using acetaldehyde inhalation as an example, CA EPA defines $90 \mu \mathrm{g}$ per day as the level below which risk will be less than 1 in 100000 . On the basis of a single cigarette and using the FTC smoking method with no allowance for compensation, only one cigarette marketed in 1992 met this standard according to measurements made by Philip Morris. ${ }^{5}$ Even for that cigarette (the lowest tar version of RJ Reynold's NOW brand) the use of two per day would have exceeded the limit. For a smoker to be able to use two packs a day the amounts of acetaldehyde in cigarette smoke would need to be reduced by a factor of 40 to 500 .

While this type of analysis does not take into account synergistic toxicity, it can be an important first step in reducing the toxicity of these products. As values for combined effects become available the standards could be reduced if needed. The interesting thing to consider is that if these realistically low values are recommended widely enough and have the scientific support of the public health community, it will be very difficult for the cigarette companies, elected officials or attorneys to ignore them.

Tobacco Control 2002; 1 1:287-288
Dr William A Farone joined Philip Morris, Inc in 1976 and became director of applied research of Philip Morris USA, Inc in 1977, charged with helping the company diversify away from the cigarette business and developing technology for safer cigarettes. His employment was terminated in 1984 and he started his own technology development company which develops environmentally benign chemical and energy processes and products. He has served as president and CEO of Applied Power Concepts, Inc since 1987. Previous to his employment with Philip Morris he was vice president of research \& development for PVO International, Inc, director of scientific research for Lever Brother Company, and associate professor of chemistry at Virginia State University. He has over 70 technical publications and patents in diverse areas such as bioremediation, wind energy, biomass hydrolysis, fermentation, electromagnetic phenomena, spectroscopy, and chemistry. In 1994 he became a consultant to the US Food and Drug Administration in their attempt to regulate the tobacco industry and has testified as an expert and fact witness against the tobacco industry since 1996.

\section{Author's affiliation}

W A Farone, Applied Power Concepts, Inc, 411 East Julianna Street, Anaheim, CA, 92801 USA

Correspondence to: William A. Farone, PhD; farone@appliedpowerconcepts.com

\section{REFERENCES}

1 Kozlowski LT, Strasser AA, Giovino GA, et al. Applying the risk/use equilibrium: use medicinal nicotine now for harm reduction, Tobacco Control 2001;10:201-3.

2 Breland AB, Evans SE, Buchhalter AR, et al. Acute effects of Advance ${ }^{\mathrm{TM}}$ : a potential reduced exposure product for smokers. Tobacco Control 2002;1 1:376-8.

3 Philip Morris. Philip Morris internal annual cigarette information reports: November 1985, Bates No. 2050081090-1 185; March 1986 Bates No. 2050080635-0724; March 1987 Bates No. 2050100253-0342; November 1988 Bates No. 2050098945-9036. URL:

www.tobaccodocuments.com

4 California Environmental Protection Agency, Reproductive and Cancer Hazard Assessment Section, Office of Environmental Health Hazard Assessment. Proposition 65 status report, no significant risk levels for carcinogens and maximum allowable dose levels for chemicals causing reproductive toxicity. March 2002

5 Philip Morris. Philip Morris internal document: 11 May 1994, Bates No. 2047344082-084, URL:

www.tobaccodocuments.com. See also Philip Morris document: 25 April 1994, Bates No. 2050918085-96, D Leyden to Dr C Ellis, Relationships of nicotine, acetaldehyde and tar to sales data. 